Research Journal of Physical Education, Vol. 16, No. 6, March, 1972, pp. 309-18.

\title{
THE SOCIAL FACTORS AFFECTING THE FORMATION AND DEVELOPMENT OF BASEBALL TEAMS IN THE COMMUNITY
}

\author{
K. KAGEYAMA \\ Tokyo Metropolitan University \\ T. TERASAWA \\ Toyota Higher Technological College \\ H. NISHIGAKI \\ Aichi Prefectural University of Arts \\ T. NAKASHIMA \\ Nagoya University
}

\begin{abstract}
This survey was conducted in order to clarify the factors affecting the formation and the development of the Japanese kitten baseball clubs in the community. When conducting the survey, specific observational emphases were put on the two main group functions, i.e., maintenance function and performance function, external conditions of the clubs, and various characteristics of the members composed of groups. This investigation was performed consecutively in three years from 1967 to 1969 ; in the first year, to clarify mainly the social background, in the second year, the social factors affecting the development of teams, and in the third year, the social factors causing the disintegration of baseball teams. The total number of baseball teams surveyed were 149. Conclusions drawn from this survey were as follows ;

1. External social conditions were the most important factors affecting the formation, maintenance, and development of the baseball teams in the community.

2. The maintenance and improvement of teams themselves were more complicated and difficult than the formation of the teams.

3. Four factors were found to be necessary for maintaining and devloping a team.

4. The most decisive factors concerned with the maintenance and the development of a baseball team in a community seemed to be the social conditions which affected the team's performance function.
\end{abstract}

\section{The Purpose and the Significance of the Investigation}

The investigation has been made for the purpose of clearing the social factors functioning in the formation, development and disintegration of groups in kitten baseball, one of the most popular community sporting groups in our country. It is rightly supposed that there must be various social factors working in the forming, development and breaking down of sporting groups and, therefore, we have found it important to make them clear in order to provide the necessary conditions for the community sports clubs. 
As generally known, sporting clubs such as those in the U.S.A. or European countries are not yet fully developed in Japan. It is, however, characteristic that we have many sporting groups corresponding to their clubs in our schools and at our work sites. Though there are also groups founded in neighborhoods, the number of these is quite small and few of them have the facilities for their exclusive use. In view of the present situation, we are now earnestly required of advancement of community sports clubs from the standpoints of not only life-long physical education but of furtherance of mass sports. Therefore, it should be noted that the groups we have dealt with are not what one calls clubs but teams of some kind with rather temporary characters. Within the character of a "team", the groups are comparatively easily formed and are easily influenced by social conditions.

Baseball clubs of schools were excluded here, because schools are obliged to have various clubs for the extra-curricular activities and those clubs are a little different in character from any other.

In order to examine the social factors working on formation, maintenance and development of groups, we must observe the group from many angles. First, it will be necessary to note two main group functions, namely "maintenance function" and "performance function" as these are called. T. Parsons 1) stated four important functions which are known generally as A, G, I, L. Here we have divided A and G functions into "performance functions" and $I$ and $L$, into "maintenance functions". So we suppose it to be very important to make clear the relationship between the two group functions and the formation and development of a group.

Second, we must on one hand deal with internal group factors such as the role or status structure and group morale, and on the other hand it is necessary to deal with the external conditions of groups such as the facilities and peculialities of the community in which the team was formed to come into play. M. Olmsted ${ }^{2)}$ classified those methods of approach as the internal approach and external approach. This investigation aimed at the latter rather than the former. Supposedly it might also be required to deal with the cultural factors such as the traditions or values connected with sport in the community. But they cannot be dealt with sufficiently in this investigation.

Third, the conditions of individual members should be taken into consideration as well as those of groups, for the individual makes up the foundation of the group. The character of a group naturally depends on the various features of the members such as age, sex, occupation, social status, etc.

Though the points of view above were taken into consideration in advance, the investigation has not been done within the clear hypothetical framework. Actually various factors which can't easily be divided are mixed so complicatedly that it becomes difficult to set the hypothetical framework neatly.

\section{The Main Investigations up to Date}

Considerably many investigations have been concerned with the sporting groups in our country. However, they have been in most cases concerned only with the school athletic 
clubs. The followings will be the representative study of these groups.

The first is a classical study on the educational and social aspects of high school athletic clubs by K. Katō and others ${ }^{3)}$. It was a conglomerate study of athletic groups, group members and social conditions. The second study is by Niwa and Takemura ${ }^{4)}$ concerning the relationship between athletic groups and personalities of the group members. This focuses upon the socio-psychological aspects of athletic organization. The third study is Kageyama's ${ }^{5)}$ study of social aspects of high school athletic clubs in which the various social factors working on the participation in the clubs was illustrated. Besides these studies, Yokoyama ${ }^{6)}$ and Tanaka 7) have conducted interesting studies.

Their studies were to have included community groups outside of school clubs but unfortunately have yet to be fully completed. We feel that it would be a feature of this study to examine the social factors involved in community sporting groups as the social organizations. We also feel that the studies of top athletes by Takenoshita and others ${ }^{8)}$ and his analytical study 9) of persons participating in sporting activities both have deep relationship to this which we are now pursuing. According to the National Survey of Sports Participants by the Prime Minister's Office in 1965, the percentage of males (ages from 18 to 59 years) who have entered sporting clubs was $14.4 \%$, of which men who entered the clubs within their work site were $9.1 \%$; Community clubs, $2.5 \%$; School clubs $2.2 \%$; and Others $1.4 \%$.

There are also some studies concerning the clubs which were originated at the work sites. Our survey of the industrial recreation in Ichinomiya City 10) was concerned with the investigation as to how much affect size of companies would have on the formation of sporting groups.

\section{The Methods and the Subjects of the Investigation}

This investigation is to integrate the results of following three surveys. These are;

(1) The investigation which aimed to make clear chiefly the social background of baseball teams. Interviews with the representatives of teams and the questionnaires were the methods used. Subjects of inquiry were 149 baseball teams of three "Ku" or wards in Nagoya (population about 2,000,000.), and out of these, 106 answers were the valid sample which means to get replies from each group member also. The year of the inquiry was 1967.

(2) The investigation which wanted to clarify the social factors working on the development of baseball teams. The method used was to send questionnaire cards (postal) to the each team. Though the subjects of inquiry were 1,522 baseball teams participating in Aich Kitten Baseball Federation, the number of teams chosen by random sampling was 250 . Out of which 146 teams and their 419 members were the valid samples. The year of inquiry was 1968.

(3) The investigation which purposed to examine the social factors functioning in the disintegration of baseball teams. The method of inquiry was to analyze 4 neighborhood teams that broke up. The year of inquiry was 1969. 


\section{The Findings and Discussion}

(1) Social factors affecting the formation of teams.

Table 1 shows group bases from which the teams were born. According to this table, neighborhood team amounts to less than $10 \%$ of the total, while three-fourths of all the teams were formed at work sites or in business establishments. Consequently, the more business establishments the community has, the more baseball teams there are, and the number of the teams is not always in proportion to the population of the community.

Table 2 shows the teams within business establishments in relation to the scale of enterprise. Statistically, the larger the scale of the establishment, the larger percentage there is of teams organized. Indeed the $97.5 \%$ of the business establishments with more than 300 workers have their baseball teams, but the percentage fall down to $0.04 \%$ in those with less than 29 workers. Thus, we can say that business

Table 1. Number and its percentage of the teams in relation to the group bases.

\begin{tabular}{l|c|c}
\hline \multicolumn{1}{c|}{ Group bases } & Number of teams & $\%$ \\
\hline Business establishment & 112 & 75.1 \\
Union of companies & 19 & 12.8 \\
Neighborhood & 19 & 12.1 \\
\hline \multicolumn{1}{c|}{ TOTAL } & 149 & 100.0 \\
\hline
\end{tabular}

(From the survey (1) aforementioned.) establishments are more advantageous in

Table 2. Number of the teams in relation to the scale of enterprise and its proportion to the whole establishments.

\begin{tabular}{c|c|c|c}
\hline $\begin{array}{c}\text { Scale of } \\
\text { enterprise }\end{array}$ & $\begin{array}{c}\text { Number of } \\
\text { establishments }\end{array}$ & $\begin{array}{c}\text { Number of } \\
\text { teams }\end{array}$ & $\%\left(\frac{\mathbf{B}}{\mathbf{A}} \times 100\right)$ \\
\hline (workers) & & 8 & \\
-29 & 22,489 & 37 & 0.04 \\
$30-99$ & 733 & 28 & 4.8 \\
$100-299$ & 121 & 39 & 23.1 \\
$300-$ & 40 & \multicolumn{2}{c}{ (From the survey (1) } \\
\hline
\end{tabular}

(From the survey (1).)

forming teams than neighbourhood groups and that big establishments are more advantageous than smaller ones.

As for the immediate motive to form baseball teams, $68.5 \%$ of the teams mentioned "the Ball-Games" of community or business unions as the greatest factor. Then comes "Leaders and Sponsors" $(15.1 \%)$ and only $1.4 \%$ of them answered "Owning facilities". Those replies seem to reveal the peculialities of sporting groups in our country which are the so-called "game-first" philosophy and tendencies to break down easily for the lack of adequate facilities. 
Together with the factors above, we can't overlook the member's attributes. Figure 1 reveals the character of the members of the teams. Of all the items, we can't disregard the item of "experience of athletic clubs in school", because $85.2 \%$ of baseball players made this answer, while the answers of whole persons in our country amounts only to 20 to $30 \%$ at best. Besides we can't neglect the items such as "age" and "marital status" of participants in baseball teams, because the majority of mem. bers are unmarried youngsters. Therefore it is necessary to point out the importance of the existence of such people in the community or the establishments.

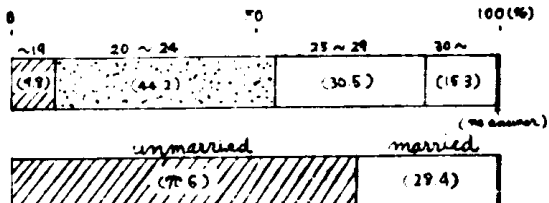

Warringe

School Carree?

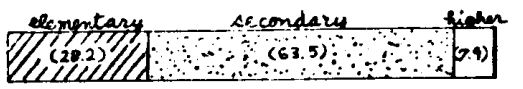

Annue: Incone (tnousends yea)

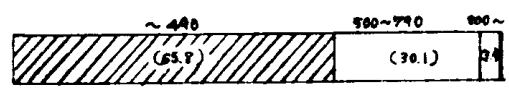

Annual Holidays with

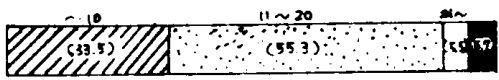

Eaeinese of Getting
the Paid Hollday

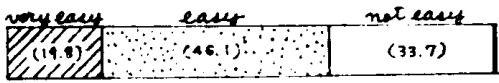

Experience of Athleti Clube in Sehool

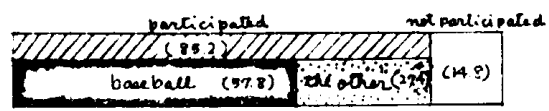

Fig. 1. Features of the Participants in Community Baseball Teams. (F rom the survey (2).)

(2) Social factors affecting the maintenance and development of teams.

Table 3 shows the "age of teams" besides the group bases of the teams. The "age of teams" means the years since the team was established to the period of this inquiry. As the table shows, not only the teams of business establishments are older than others but also the teams of bigger establishments are, in general, older than the smaller ones. These tendencies are also true of the forming of the teams. Therefore, it can be supposed that the scale of business establishments has a great influence not only on the forming but also on the maintenance of teams. Also, the age is connected with the facilities which can always be used, and teams with good facilities are generally older than others.

The teams are classified as follows into four groups- I, II, III and IV mainly according to the level of activities. In this we would like to consider the factors working on the activi-

Table 3. Number and percentage of the teams over 7 years old besides the group bases.

\begin{tabular}{|c|c|c|c|c|}
\hline \multirow{2}{*}{\multicolumn{2}{|c|}{ Group bases }} & \multirow{2}{*}{$\begin{array}{l}\text { Number } \\
\text { of all teams }\end{array}$} & \multicolumn{2}{|c|}{ Teams over 7 years old. } \\
\hline & & & Number & $\%$ \\
\hline \multicolumn{2}{|c|}{ Business establishment } & 85 & 37 & 43.5 \\
\hline \multirow{5}{*}{$\begin{array}{c}\text { Scale of } \\
\text { them }\end{array}$} & (workers) & & & \\
\hline & -29 & 7 & 2 & 28.6 \\
\hline & $30-99$ & 22 & 7 & 31.8 \\
\hline & $100-299$ & 22 & 9 & 41.0 \\
\hline & $300-$ & 34 & 19 & 55.9 \\
\hline \multicolumn{2}{|c|}{ The other } & 21 & 7 & 33.4 \\
\hline
\end{tabular}

(From the survey (1).) 
ties. Here, we would take the level of activities as main index of the group development. The groups are;

I. Very active teams (those playing more than once a week)

II. Teams of average activity (those playing more than once a month)

III. Teams not so active (those playing less often than two types above)

IV. Teams seldom do activity (those that exist only in name)

In this regard, we would like to mention the percentage of each type $\mathrm{A}-7.5 \%, \mathrm{~B}-40.4 \%$, $\mathrm{C}-50.7 \%$ and $\mathrm{D}-1.4 \%$. Note that more than a half of all teams belong to types $\mathrm{C}$ and $\mathrm{D}$.

Table 4 shows the relationship of these types to the various factors. According to the table, we know that the level of activity is deeply related with the following factors;

1. Whether the member can get a "paid holiday" or not. (To be able to get holidays at any time he likes.)

2. The scale of their business establishments.

3. Whether or not they have facilities for their preferential use.

4. Unity of members in the team. (group cohesiveness)

5. Results of recent games.

6. Whether or not they have leaders who coach them.

Summing up the factors above, we founed the following requirements are important for the development of the team;

1) To be cohesive in the team..... or to have a homogeneous base within the team membership and steadiness of the group bases.

2) To set an attainable goal..... or to have "Ball-Games" which can be their purpose

Table 4. Relationship of the Team Types by Activity Level to the Various Factors about the Member and Group.

\begin{tabular}{l|c}
\hline \multicolumn{1}{c|}{ Factors } & $\begin{array}{c}\text { Significant Level by Chi-Square Test. } \\
(* \cdots \mathrm{P}<0.05,\end{array}$ \\
\hline 1. About the Member. & \\
(1) Age & \\
(2) School Carreer & \\
(3) Income \\
(4) Annual Holidays with Pay \\
(5) Easiness of Getting the Paid Holiday \\
(6) Experience of Baseball Club in School \\
\hline 2. About the Group. \\
(1) Scale of the Establishment \\
(2) To Have Facilities for Preferential Use \\
(3) Annual Expense \\
(4) Unity of Members \\
(5) Results of Recent Games \\
(6) Age of the Team \\
(7) To Have Leaders who Coach them
\end{tabular}

(From the survey (2).) 
of their efforts.

3) To have proper leaders appropriate to the subject (baseball) of the group.

4) To be under the favourable conditions where they can fully operate as a team. Particulary to have the facilities necessary for the activity.

The four requirements above show, in conclusion, that it is important for a team to be under the circumstances where they can operate harmoniously both on its "maintenance function" and its "performance function". And it can be also supposed that the conditions concerning the "performance function" are particulary important for the development of baseball teams.

(3) Social factors working on the breaking down of teams.

The following four concrete instances are typical of most teams that disintegrate. Marking clear the social factors which brought on the break down will at the same time be useful in difining those factors having to do with the maintenance and the development of teams. In the analysis of these groups, we refered to Zalesnik's ${ }^{11)}$ point of view. He stated four necessary requirements for a group to survive, standing up against disintegration, which are "the well-defined structure", "the interrelated structure", "the fulfilment of a leadership function" and "harmony with group purpose".

\section{(Team A)}

The team was established by ball-lovers in a company headed by Mr. A who had much baseball experience. Many of the members were poor in experience and skill. Nevertheless, Mr. A gave full play to his leadership and the team was active. Yet, since its third year some members have been removed from the company houses and the rest of them found it difficult to fill up the vacancies. They called for the persons from outside company houses. It followed that the difference in living conditions caused an unsettlement among the members. Temporary members were later asked to take part in the official games. Such confusion brought disorder to the status and roles within the team and broke the team down in its fourth year.

(Team B)

The team was formed by young workers of small business establishments which were located rather near one another. In its first year they were vigorously active because they were made up of youngmen of nearly the same age. They had no temporary members. The roles and positions were clear and they attained the annual goal..... participating in 15 games a year. But in its second year, Mr. B who was the captain who managed the members had less spare time to get facilities and perform liaison than he could in the first year. Consequently they had less gemes and practice-games.

They found it necessary to win the official games to achieve the goal of the team. As a result only regular members were asked to join games and the purpose of irregular members was not fulfilled. The contradiction occured between "to win" and "to take part" or rather between the "goal of team" and the "goal of individual". In addition to the contradiction, the fact that both Mr. A and Mr. B were as young as the members made the solution even more difficult. The leaders were performing their leadership roles without 
dissolving the opposition of two sub-groups: regular members and irregular members. Eack: of these sub-groups went on growing and brought the team breaking dow $n$ in its second year.

(Team C)

The team was established by Mr. C, a tea-house keeper and sponsor of the team, who called together the baseball-lovers of his neighborhood and constantly took care of the team from its start to the breaking down. Members were chiefly made up of youngsters of the shopping district, who added community solidality. Members of the team frequently changed, however, and the change formed the sub-groups in the team. While the members were much interested in baseball and $\mathrm{Mr}$. C played a strong leadership role, the team was rather stable by clear role and status structure.

In their early days they had facilities and were united in that they have a common base, the neighborhood. They could cultivate their skills and established successfully the foundation of the team. As they won more games, they took part in the "Ball-Games" of the ward federation and thus they attained their goal. Nevertheless the team broke down in its sixth year when Mr. C left, because they lost their leadership.

(Team D)

The team was made by Mr. D, a laundry keeper, who called together his customers and workers of small business establishments in his neighborhood. Mr. D undertook most of the team business. As the $60 \%$ of members were not experienced when the team was started, there was another leader Mr. E, the captain, who coached the players. Founded in a commercial district, team had the members with district unity, and the internal structure of team was stable (interrelated).

The goal of the team was to have tournament games and practice as much as possible. In its early days they played games and practiced almost every Sunday using school grounds or vacant lots and achieved the goal of the team. Afterwards when they were shut out from school ground, the activity became less active. The team, as a result, joined the federation of the ward to achieve its original goals. However, the "Ball-Games" of the federation were held only five times a year and this was below their objective. At about this time, the vacant lots were filled up and they lost their place to practice. The team broke down in its third year being unable to attain even its minimum goal.

As we could see in the examples above, the factors for breaking down vary with individual teams. The main factors of each one will be summed up as follows;

* Team A …... The foundation of the group grew weaker and the unity dissolved, which led to the breaking down of the team.

* Team B ….. The goal of the members were divided when they faced the "Ball-Games", and the team itself was dissolved into two by the internal friction.

* Team C..... The required function of leadership died out by the removal of the leader, causing the team to break down.

* Team D…. They lost the facilities they used and became unable to continue practice and playing games. 
These results illustrate the importance of the neccessary factors previously stated. Furthermore we must point out that team which were over 10 years old were not lacking any of the 4 factors, namely, a sound group base, attainable goal, appropriate leadership and favorable environment.

\section{Conclusion}

From the findings in the preceding chapters, we can state:

(1) Of various social factors concerning the forming, maintaining and developing baseball teams in the community, the external social conditions should be of particular attention. (In previous investigations of small groups, conclusions were apt to take into account only the internal conditions of the groups.)

(2) In forming teams, a good group foundation seems to be more important factor than any other.

(3) Maintaining and improving teams is much more complicated than the initial formation of the group. The fact that there are many cases where the teams broke up soon after they were established (cf. the age of teams) and there were also many which seldom played proves the necessity of the various factors.

(4) In maintaining and developing a team, the following four factors are necessary:

1. A steady group foundation.

2. "The Ball-Games" appropriate to the group purpose.

3. Leaders who can help the players develop skills.

4. Adequate conditions and facilities for practice and play.

(5) When a team lacks any one of the four requirements, there is always a danger of disintegration, but if all the four are satisfied the team stands a good chance of success.

(6) In conclusion, the social conditions especially concerned with the "performance function" seem to be decisive factors in the maintenance and development of a baseball team.

\section{Literature Cited}

1) T. Parsons, et al.: Toward a General Theory of Action, 1954. Translated into Japanese by M. Nagai, et al., Nihon Hyoron-sha, 1960. A, G, I and L mean "adaptation", "goal gratification", "integration" and "latent-pattern maintenance and tension management", respectively.

2) M. Olmsted: The Small Group, 1961. Translated into Japanese by Baba, et al., Seishin-shobo, 1963.

3) K. Katō, et al: Sociological and Educational Study of Athletic Clubs and Athletes in High School. Research J. of Phy. Edu., Vol. III, No. 1, 1958.

4) T. Niwa \& A. Takemura: Relation to School Athletic Clubs and Personalities of the Members. R.J.P.E., Vol. 11, No. 1, 1966.

5) K. Kageyama: The Social Factors Working on the Participation in Athletic Clubs in High School. Annual Report of Sociological Approach Section in Japanese Society of Phy. Edu., No. 4, 1965.

6) I. Yokoyama: A Sociological Study of Sports Clubs in University. Research Bulletin of Education, Faculty of Fukui University, Vol. VII, No. 18, 1968. 
7) S. Tanaka: Case Studies of First Class Athletic Clubs in High School. Research Bulletin of Nihon University, No. 12, 1970.

8) K. Takenoshita, et al.: A Study of Social Backgrounds of Top Athletes in Japan. R.J.P.E., Vol. 9, No. 1, 1964. ; A Sociological Study of Top Athletes in Japan. R.J.P.E., Vol. 15, No. 5, 1971.

9) K. Takenoshita: The Social Structure of the Sport Population in Japan. International Review of Sport Sociology, Vol. 2, 1967.

10) K. Kageyama, et al.: A Survey Report of Recreation Activities in Industries at IchinomiyaCity, 1968.

11) A. Zaleanik: Worker Satisfaction and Development, 1956. Japanese translation by Noda, et al., Seishin Shobo, 1958. 